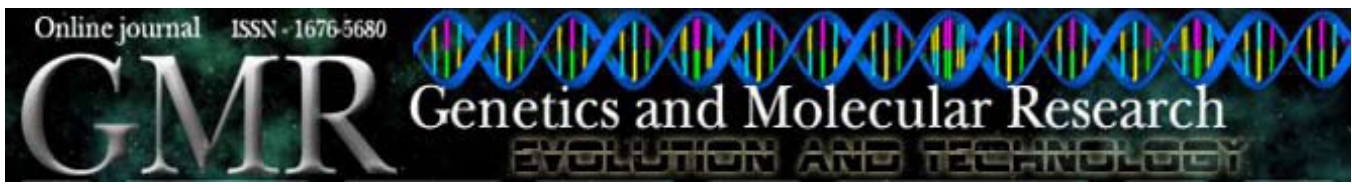

\title{
PCR-RFLP genotyping protocol for chicken $M x$ gene G/A polymorphism associated with the S631N mutation
}

\author{
L. Sironi ${ }^{1,2}$, P. Ramelli ${ }^{1}$, J.L. Williams ${ }^{1}$ and P. Mariani ${ }^{1}$ \\ 'Parco Tecnologico Padano, CERSA, Lodi, Italy \\ ${ }^{2}$ DIPAV, Università degli Studi di Milano, Milano, Italy \\ Corresponding author: P. Mariani \\ E-mail: paola.mariani@tecnoparco.org
}

Genet. Mol. Res. 9 (2): 1104-1108 (2010)

Received February 21, 2010

Accepted March 20, 2010

Published June 11, 2010

DOI 10.4238/vol9-2gmr811

\begin{abstract}
The $M x$ (myxovirus resistance) gene codes for a protein with antiviral activity. Non-synonymous G/A polymorphism at position 2032 of chicken $M x$ cDNA results in a change at amino acid 631 of the Mx protein. This mutation has been shown to affect the antiviral activity of the Mx molecule, although recent studies have not confirmed this effect in response to some influenza strains. Nevertheless, the G/A polymorphism could be important for the chicken's response to other viruses. A robust PCR-RFLP protocol for genotyping chicken $M x$ gene polymorphism associated with the S631N mutation was developed. The F primer anneals to the last intron of the $M x$ gene, and the $\mathrm{R}$ primer anneals to the last exon of the gene, with an expected PCR product of $299 \mathrm{bp}$. PCR products were digested with Hpy8I. This enzyme cuts the sequence 5'-GTN|NAC-3', 2 bp downstream of the $M x$ polymorphism for the $\mathrm{G}$ allele, whereas the fragment containing the A allele is not
\end{abstract}


cleaved. One hundred and twenty-seven chickens (commercial broilers, White Leghorn and New Hampshire) were genotyped using this protocol, and genotyping data were validated by sequencing. Full identity of results between the two genotyping methods was observed for all 127 samples, proving the reliability and robustness of this PCR-RFLP protocol.

Key words: Chicken; PCR-RFLP; Avian influenza virus; $M x$ gene; S631N mutation

\section{INTRODUCTION}

Mx proteins have antiviral activity specific for different viral families, and are found in several vertebrate species (reviewed in Haller et al., 2007). In particular, the mouse Mx1 protein has been shown to confer resistance to influenza A viruses (Salomon et al., 2007; Tumpey et al., 2007).

In chicken, the effect of the Mx proteins is not as clear: initially, in vitro study demonstrated that the Mx protein had no antiviral activity against influenza virus in duck (Bazzigher et al., 1993) and chicken (Bernasconi et al., 1995), but later studies (Ko et al., 2002) showed that the chicken Mx variant Asn631 conferred antiviral activity against vesicular stomatitis virus and $\mathrm{H} 5 \mathrm{~N} 1$ influenza virus on transfection into mouse $3 \mathrm{~T} 3$ cells.

The non-synonymous G/A polymorphism at position 2032 of chicken $M x$ cDNA (accession No. Z23168), resulting in the substitution of serine with asparagine at position 631 of the Mx protein, seems to influence the antiviral activity of the molecule (Ko et al., 2002). However, no association was found between the $M x$ genotype for the G/A polymorphism affecting amino acid position 631 and the survival of chicken experimentally infected in vivo with a highly pathogenic H7N1 avian influenza virus (Sironi et al., 2008).

Similar results were obtained by Benfield et al. (2008) in their study showing that the Asn631 allele of chicken $\mathrm{Mx}$ is unable to inhibit in vitro replication of 5 influenza strains.

Several studies have investigated the allele frequency of the $M x 2032$ G/A polymorphism in the chicken using a variety of methods: mismatched polymerase chain reaction-restriction fragment length polymorphism (PCR-RFLP) (Seyama et al., 2006), electrophoresis of PCR products on polyacrylamide gels ( $\mathrm{Li}$ et al., 2006), and sequencing (Balkissoon et al., 2007).

In a previous study (Sironi et al., 2008), $M x$ genotyping for the 2032 polymorphism was carried out by both direct sequencing and PCR-RFLP analysis to compare the genotypes obtained. Some discrepancies were initially observed in the genotype data obtained with the two methods, due to an $\mathrm{A} / \mathrm{G}$ single nucleotide polymorphism in the sequence of the $\mathrm{F}$ primer used for the PCR-RFLP, leading to the preferential amplification of one of the two alleles. New primers and PCR-RFLP protocol were established. The latter PCR-RFLP-based genotyping protocol that does not require the creation of mismatches (Seyama et al., 2006) is here described.

\section{MATERIAL AND METHODS}

Primers were designed based on the $M x$ genomic sequence of accession No. DQ788615, as follows: forward (F) 5'-GCACTGTCACCTCTTAATAGA-3' and reverse (R) 5'-GTATTGGTAGGCTTTGTTGA-3'. The F primer anneals to the last intron of the $M x$ 
gene, and the R primer anneals to the last exon of the gene. The expected PCR product had a length of $299 \mathrm{bp}$.

PCR was carried out in a total volume of $15 \mu \mathrm{L}$, with $30 \mathrm{ng}$ genomic DNA, 6 pmol of each primer, $1.5 \mu \mathrm{L} 10 \mathrm{X}$ buffer, $1.5 \mathrm{mM} \mathrm{MgCl}_{2}, 0.2 \mathrm{mM}$ of each dNTP, and $1 \mathrm{U}$ AmpliTaq Gold (Applied Biosystems). The thermal cycle was as follows: $95^{\circ} \mathrm{C}$ for $10 \mathrm{~min}, 35$ cycles of $94^{\circ} \mathrm{C}$ for $1 \mathrm{~min}$, annealing at $53^{\circ} \mathrm{C}$ for $1 \mathrm{~min}$, and $72^{\circ} \mathrm{C}$ for $1 \mathrm{~min}$, followed by a final extension step at $72^{\circ} \mathrm{C}$ for $10 \mathrm{~min}$. PCR products $(3 \mu \mathrm{L})$ were visualized in an ethidium bromide (EtBr)stained $2 \%$ agarose gel in $1 \mathrm{X}$ TAE buffer.

PCR products were digested with Hpy8I (Fermentas). This enzyme cuts the sequence 5'-GTN|NAC-3', 2 bp downstream of the $M x$ polymorphism for the G allele, whereas the fragment containing the A allele is not cleaved (Figure 1). The digestion reaction mixture was prepared using 12- $\mu \mathrm{L}$ PCR product, $10 \mathrm{U}$ Hpy $8 \mathrm{I}$ (Fermentas), $\mathrm{dH}_{2} \mathrm{O}$ and Tango buffer according to the manufacturer, and incubated at $37^{\circ} \mathrm{C}$ for $3 \mathrm{~h}$. Digestion products were visualized by electrophoresis through an EtBr stained 2.8\% agarose gel in 1X TAE buffer (Figure 2).

DNA was obtained from one hundred and twenty-seven chickens (commercial broilers, White Leghorn and New Hampshire), which was used for genotyping both the PCR-RFLP protocol and sequencing. Some of these data have been published previously by Sironi et al. (2008).

\section{RESULTS AND DISCUSSION}

This paper describes a robust PCR-RFLP genotyping protocol for chicken $M x$ gene polymorphism that causes the S631N mutation in the coded protein.

Primers were designed to avoid other restriction sites for the Hpy8I enzyme, and to obtain fragments of sufficient size to be easily discriminated. Following digestion with Hpy8I, a single fragment of $299 \mathrm{bp}$ was expected for the homozygous A allele, two fragments of 200 and $99 \mathrm{bp}$ in the presence of the homozygous $\mathrm{G}$ allele, and three fragments $(299,200$, and 99 $\mathrm{bp}$ ) in the presence of heterozygosity (see Figure 2).

Mismatches in the primer binding sites for PCR-RFLP genotyping methods are likely to lead to genotyping errors. In a previous study, Sironi et al. (2008) initially observed discrepancies in genotyping data obtained from sequencing and PCR-RFLP approaches. That was the result of an $\mathrm{A} / \mathrm{G}$ single nucleotide polymorphism in the $\mathrm{F}$ primer used in PCR-RFLP. The genotyping protocol described in the present study used redesigned primers that avoid this polymorphic site. In a previous study, 85 chickens from three commercial broiler lines and two experimental lines (New Hampshire and White Leghorn) were genotyped with both the PCR-RFLP protocol described here and sequencing. Full identity of results between the two methods was obtained for each of the 85 chickens (Sironi et al., 2008). Forty-two broilers from six other commercial broiler lines were spe-

\footnotetext{
GCACTGTCACCTCTTAATAGAGTACCTTCAGCCTGTTTTTTCTTCTTTTAGGAAAAAAGTCTTCACTCTTTTTTTCCCTC TCCTTGT AGGGAGCAA [A/G] TAAACGCCTGAGCAATCAGATT CCT CT GAT CATCCT CTCTACTGTCCTT CATGACT TTG GAAAT TATT TGCAGACCTCAATGT TGCATCTCT TGAAGGAAAAGAAGAAATAAACTATT TACTCCAAGAAGATCATGAA GCTGCTAACCAGCAGAAGT TACTGACCAGCAGAATT AGTCACCTCAACAAAGCCT ACCAATAC
}

Figure 1. Nucleotide sequence of the $M x$ gene fragment (bases 20670-20968 of accession No. DQ788615). The intron is in italics and coding sequence is in normal type. Primers are shown shadowed, and the G/A 2032 polymorphism causing the $\mathrm{S} 631 \mathrm{~N}$ mutation is in square brackets. The Hpy8I restriction site is underlined. 


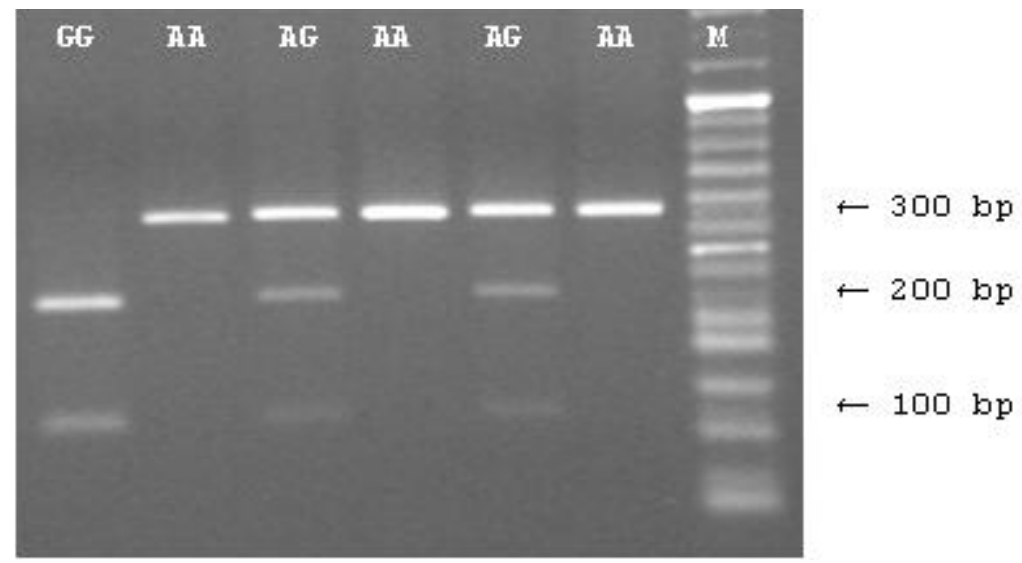

Figure 2. Examples of PCR-RFLP products after digestion with Hpy8I and separation by electrophoresis through a $2.8 \%$ agarose gel. Lane $G G=$ homozygous $\mathrm{G}$ allele; lanes $A A=$ homozygous $\mathrm{A}$ allele; lanes $A G=$ heterozygous; $\mathrm{M}=$ ladder.

cifically genotyped for the present paper. Recently, three amino acid mutations downstream of the S631N site have been reported (Berlin et al., 2008). One of these seems to be due to a nucleotide substitution within the $\mathrm{R}$ primer sequence used in the protocol described here. Nevertheless, the presence of this polymorphism was not confirmed in the samples analyzed in the present study.

The $M x$ gene has a large number of repeat sequences making sequencing of the gene and genotyping error-prone (Ommeh $\mathrm{S}$, personal communication). The present study shows the need to carefully choose the $M x$ gene template region for primer design and to carry out repeated genotyping, preferably using different primer sets.

\section{ACKNOWLEDGMENTS}

The authors thank Dr. Steffen Weigend (Institute of Farm Animal Genetics, Friedrich Loeffler Institut, Mariensee, Germany), for providing the restriction enzyme for the PCR-RFLP protocol, and Dr. Chiara Gorni (Parco Tecnologico Padano, Lodi, Italy) and Ms. Sheila Ommeh (International Livestock Research Institute, Nairobi, Kenya) for valuable discussions.

\section{REFERENCES}

Balkissoon D, Staines K, McCauley J, Wood J, et al. (2007). Low frequency of the Mx allele for viral resistance predates recent intensive selection in domestic chickens. Immunogenetics 59: 687-691.

Bazzigher L, Schwarz A and Staeheli P (1993). No enhanced influenza virus resistance of murine and avian cells expressing cloned duck Mx protein. Virology 195: 100-112.

Benfield CT, Lyall JW, Kochs G and Tiley LS (2008). Asparagine 631 variants of the chicken Mx protein do not inhibit influenza virus replication in primary chicken embryo fibroblasts or in vitro surrogate assays. J. Virol. 82: 7533-7539.

Berlin S, Qu L, Li X, Yang N, et al. (2008). Positive diversifying selection in avian Mx genes. Immunogenetics 60: 689-697.

Bernasconi D, Schultz U and Staeheli P (1995). The interferon-induced Mx protein of chickens lacks antiviral activity. $J$. Interferon Cytokine Res. 15: 47-53. 
Haller O, Stertz S and Kochs G (2007). The Mx GTPase family of interferon-induced antiviral proteins. Microbes Infect. 9: 1636-1643.

Ko JH, Jin HK, Asano A, Takada A, et al. (2002). Polymorphisms and the differential antiviral activity of the chicken Mx gene. Genome Res. 12: 595-601.

Li XY, Qu LJ, Yao JF and Yang N (2006). Skewed allele frequencies of an Mx gene mutation with potential resistance to avian influenza virus in different chicken populations. Poult. Sci. 85: 1327-1329.

Salomon R, Staeheli P, Kochs G, Yen HL, et al. (2007). Mx1 gene protects mice against the highly lethal human H5N1 influenza virus. Cell Cycle 6: 2417-2421.

Seyama T, Ko JH, Ohe M, Sasaoka N, et al. (2006). Population research of genetic polymorphism at amino acid position 631 in chicken Mx protein with differential antiviral activity. Biochem. Genet. 44: 437-448.

Sironi L, Williams JL, Moreno-Martin AM, Ramelli P, et al. (2008). Susceptibility of different chicken lines to H7N1 highly pathogenic avian influenza virus and the role of Mx gene polymorphism coding amino acid position 631. Virology 380: $152-156$.

Tumpey TM, Szretter KJ, Van Hoeven N, Katz JM, et al. (2007). The Mx1 gene protects mice against the pandemic 1918 and highly lethal human H5N1 influenza viruses. J. Virol. 81: 10818-10821. 